\section{Serial STIR magnetic resonance imaging correlates with clinical score of activity in thyroid eye disease}

Abstract

Purpose To assess the correlation between inflammatory activity in extraocular muscles measured with serial short tau inversion recovery (STIR) sequence magnetic resonance imaging (MRI) scans and clinical disease activity in thyroid eye disease.

Methods In this retrospective study, 22 patients with thyroid eye disease who had undergone serial MRI scans using the STIR sequence were assessed. The signal intensity ratio (SIR) of the most inflamed extraocular muscle was compared with the Mourits score (a clinical measure of thyroid eye disease activity).

Results The SIR value has previously been shown to correlate with clinical activity of thyroid eye disease. In a particular patient the SIR value increases in proportion with the clinical features of the disease as assessed by the Mourits rating system. When the change in STIR sequence MRI is compared with the change in Mourits score rating for a given patient the correlation is highly significant $(p<0.001)$.

Conclusions This study confirms that serial STIR sequence MRI scans correlate with clinical disease activity. Inflammatory activity in the most inflamed muscle (as measured by SIR) reflects overall disease activity. SIR values obtained from MRI scans provide a useful measure of disease activity and may help in the monitoring and treatment of this condition.

Key words Extraocular muscles, Graves' ophthalmopathy, MRI, STIR sequence, Thyroid eye disease

Thyroid eye disease (also known as Graves' ophthalmopathy) is considered to be an autoimmune disorder of orbital tissues. The clinical features of thyroid eye disease include muscle inflammation and subsequent fibrosis, an increase in orbital volume and pressure causing proptosis, decreased orbital compliance, soft tissue inflammation and sometimes compression of the optic nerve, ${ }^{1}$ often but not always associated with alterations of thyroid function. Graves' disease refers to diffuse hyperplasia and hypertrophy of the thyroid gland associated with hyperthyroidism and proptosis. The exact pathogenesis of Graves' ophthalmopathy remains unclear. ${ }^{1,2}$

Rundle and Wilson ${ }^{3}$ described the natural history of Graves' ophthalmopathy. They divided it into a wet or active phase with progressive features, which is followed by a regressing fibrotic phase and finally a burnt-out or dry phase, associated with stable features. This staging system is referred to as Rundle's curve of disease activity. The severity and duration of the active phase are variable. The active phase may be graded and an appropriate immunosuppressive treatment regime reflects this (Table 1).

Clinical assessment of patients with thyroid eye disease involves identifying where on Rundle's curve a particular individual is situated. To this end Mourits and co-workers developed a clinical scoring system ${ }^{4}$ that uses signs and symptoms that reflect the cardinal features of inflammation (Table 2). The Mourits score is designed to reflect active and hence probably immunosensitive disease. ${ }^{4}$ Other clinical rating scores have been used to measure thyroid eye disease but include features of both active and inactive disease. ${ }^{5-7}$ Although these are based on clinical features, they do not reflect acute inflammatory activity and so were not used in this study.

Classically computed tomography (CT) scanning has been used to image orbital disease. ${ }^{8}$ However, magnetic resonance imaging (MRI) has superior soft tissue resolution and does not expose the patient to radiation. The intensity of signal derived from short term inversion recovery (STIR) sequence MRI is directly related to the water content within tissues. This has been shown to correlate with inflammatory activity. ${ }^{9,10}$ The use of STIR
E. Mayer

C. Burnett

M.J. Potts

Bristol Eye Hospital

Bristol BS1 2LX, UK

G. Herdman

J. Kabala

P. Goddard

Department of Diagnostic

Radiology

Bristol Royal Infirmary

Bristol BS2 8HW, UK

M.J. Potts

Bristol Eye Hospital

Lower Maudlin Street

Bristol BS1 2LX, UK

Received: 21 September 2000 Accepted in revised form: 19 January 2001 
Table 1. A graded approach to the management of thyroid eye disease, modified from Steel and Potts ${ }^{1}$

\begin{tabular}{|c|c|c|c|c|c|}
\hline \multirow[b]{2}{*}{ Grade } & \multirow[b]{2}{*}{ Signs and symptoms } & \multirow{2}{*}{$\begin{array}{l}\text { Duration } \\
\text { (months) }\end{array}$} & \multirow[b]{2}{*}{ Sequelae } & \multicolumn{2}{|c|}{ Treatment } \\
\hline & & & & Non-immunosuppressive & Immunosuppressive \\
\hline 1. Mild & $\begin{array}{l}\text { Slight orbital ache, ocular } \\
\text { irritation, transient } \\
\text { oedema, mild proptosis }\end{array}$ & $2-4$ & Nil & $\begin{array}{l}\text { Lubricants, topical steroid, } \\
\text { oral and topical NSAIDs }\end{array}$ & None \\
\hline 2. Moderate & $\begin{array}{l}\text { Grade } 1 \text { plus increased } \\
\text { proptosis, lid retraction } \\
\text { and conjunctival oedema }\end{array}$ & $4-8$ & $\begin{array}{l}\text { Lid retraction, } \\
\text { moderate } \\
\text { proptosis }\end{array}$ & As above & Low-dose oral steroids \\
\hline 3. Marked & $\begin{array}{l}\text { Marked proptosis and } \\
\text { chemosis, restricted eye } \\
\text { movements and diplopia }\end{array}$ & $6-12$ & $\begin{array}{l}\text { Proptosis, lid } \\
\text { retraction, } \\
\text { diplopia }\end{array}$ & As above & $\begin{array}{l}\text { Combination therapy: } \\
\text { orbital radiotherapy, } \\
\text { azathioprine, low-dose } \\
\text { steroids }\end{array}$ \\
\hline 4. Severe & $\begin{array}{l}\text { Optic nerve compression, } \\
\text { reduced acuity and colour } \\
\text { vision }\end{array}$ & $12-24$ & $\begin{array}{l}\text { Optic nerve } \\
\text { atrophy, } \\
\text { diplopia, } \\
\text { proptosis, } \\
\text { lid retraction }\end{array}$ & As above & $\begin{array}{l}\text { Intravenous steroids for } 2 \\
\text { days and combination } \\
\text { therapy (as above) }\end{array}$ \\
\hline
\end{tabular}

sequence MRI scans in thyroid eye disease has previously been established, ${ }^{11,12}$ the signal intensity ratio (SIR) having been shown to correlate with clinical measures of inflammatory activity. No study has looked at serial SIR values in patients with Graves' ophthalmopathy.

\section{Patients and methods}

Patients were selected from the Thyroid Eye Disease Clinic at Bristol Eye Hospital. Patients who had undergone more than one MRI scan were selected. Twenty-two patients were identified and all were included in this study.

Coronal MRI using the short tau inversion recovery (STIR) sequence was performed on a Seimens Magnetom Impact $1 \mathrm{~T}$ scanner with a head coil covering the eyes. Coronal T1-weighted and STIR images of the orbit were

Table 2. The Mourits grading system for the activity of Graves' ophthalmopathy ${ }^{4}$ uses the cardinal features of inflammation to measure inflammatory activity: rubor, dolor, tumour et functio laesa, excluding calor as this is difficult to assess clinically. This system gives a 10-point rating if one point is ascribed for each feature when present

Pain

Painful, oppressive feeling on or behind the globe; pain on attempted up, side or down gaze

Redness

Redness of the eyelid(s); diffuse redness of the conjunctiva

Swelling

Chemosis; swollen caruncle; oedema of the eyelid(s); increase in proptosis of $2 \mathrm{~mm}$ or more over a period of between 1 and 3 months

\section{Impaired function}

Decrease in visual acuity of 1 or more Snellen chart lines (using a pinhole) during a period of between 1 and 3 months; decrease in eye movements in any direction equal to or more than $5^{\circ}$ during a period of time between 1 and 3 months

Reproduced from Mourits et al. ${ }^{4}$ by permission of the BMJ Publishing Group. obtained. The temporalis muscle was selected as a reference standard due to its structural similarity and close anatomical relationship with the extraocular muscles. The SIR was then obtained as a ratio of signal intensity from the most severely inflamed extraocular muscle and the adjacent temporalis muscle (Figs. 1, 2). Different muscles may be at different stages of the disease. The SIR value was compared with a clinical score derived from the Mourits rating system ${ }^{4}$ at the clinic visit nearest in time to the scan date. Both these measures reflect disease activity in the more active side.

SIR values and Mourits scores were compiled independently by different researchers without knowledge of the result of the other parameter. Statistical comparisons were made using Spearman rank correlation.

\section{Results}

Of the 22 patients included in this study, 14 were female (64\%). Twenty-one patients underwent orbital radiotherapy for marked or severe thyroid eye disease, followed by a varied duration of immune suppression (with prednisolone and azathioprine). The mean duration of medical treatment after radiotherapy (prednisolone and azathioprine) was 15 months (range 1-48 months).

The most inflamed muscle in $72 \%$ was the inferior rectus, in $8 \%$ the medial rectus, in $16 \%$ the superior rectus and in $4 \%$ the lateral rectus. In $86 \%$ of patients the muscle with the highest SIR value was the same on all scans that were assessed. In 2 patients who underwent two MRI scans the muscles were different.

The main objective of this study was to compare serial SIR values with measures of clinical activity for given patients. Six patients had more than two MRI scans; of these, 5 patients had three scans and one had four. Mourits scores ranged between 0 and 9 and SIR values between 1.55 and 4.8 . 


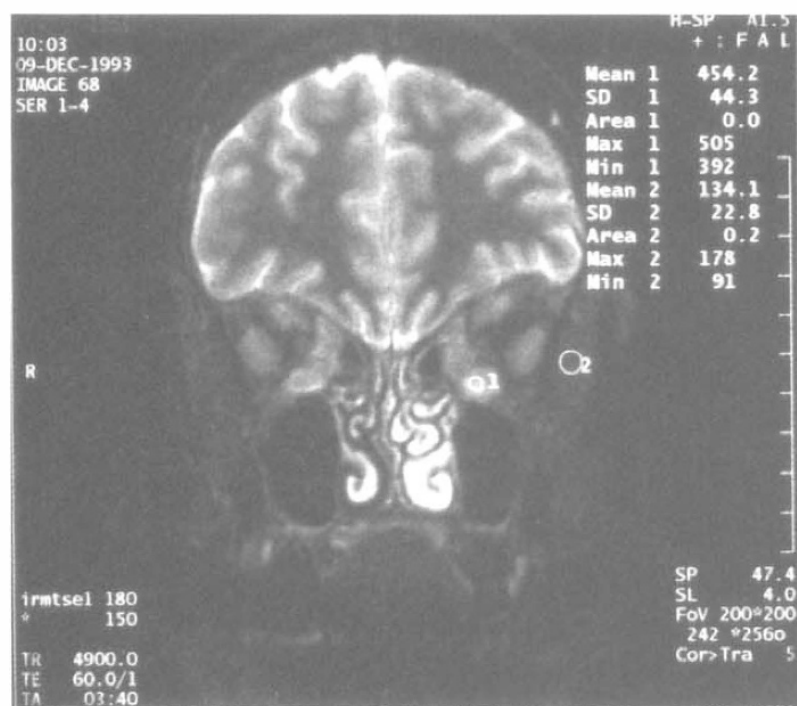

Fig. 1. A coronal STIR sequence MRI scan showing an inflamed extraocular muscle with high signal in active thyroid eye disease. Cursor 1 is around the extraocular muscle and cursor 2 is around the temporalis muscle. The ratio of signal intensity in these two muscles gives the signal intensity ratio or SIR value.

Comparing all pairs of data points (SIR and Mourits scores) for all patients revealed a correlation between the clinical thyroid eye disease activity score and muscle brightness on STIR sequence MRI (correlation coefficient $r=0.73$ ), as shown in Fig. 3. This confirms the previous observation ${ }^{11}$ that there is an overall correlation between SIR values and clinical disease activity.

When all data points for each patient are plotted (Fig. 4) it is clear that for an individual patient when the Mourits score increases (i.e. there is an increase in clinical activity of disease) the SIR value increases also. There are some exceptions, but the change in these patients is generally small. Fig. 5 shows this for the patients who have more than two paired MRI and Mourits scores available.

The change in SIR value between visits for a given patient was compared with the change in Mourits score, to test whether the SIR value can predict clinical activity. This revealed a highly statistically significant correlation (Spearman correlation $r=0.80, p<0.001$ ), as shown in Fig. 6. For statistical analysis only the change between the first pair of MRI scans was analysed, in order to avoid repeat measures on the same patient.

\section{Discussion}

Five per cent of patients with Graves' ophthalmopathy develop thyroid eye disease. ${ }^{1}$ There are three stages to the disease: the active 'wet' phase of inflammation (caused by a lymphocytic infiltration of the extraocular muscles, deposition of glycosaminoglycans and tissue oedema), followed by a regressive and fibrotic phase and then a quiescent dry (burnt-out) phase. The severity of the inflammatory process and its sequelae are variable. In

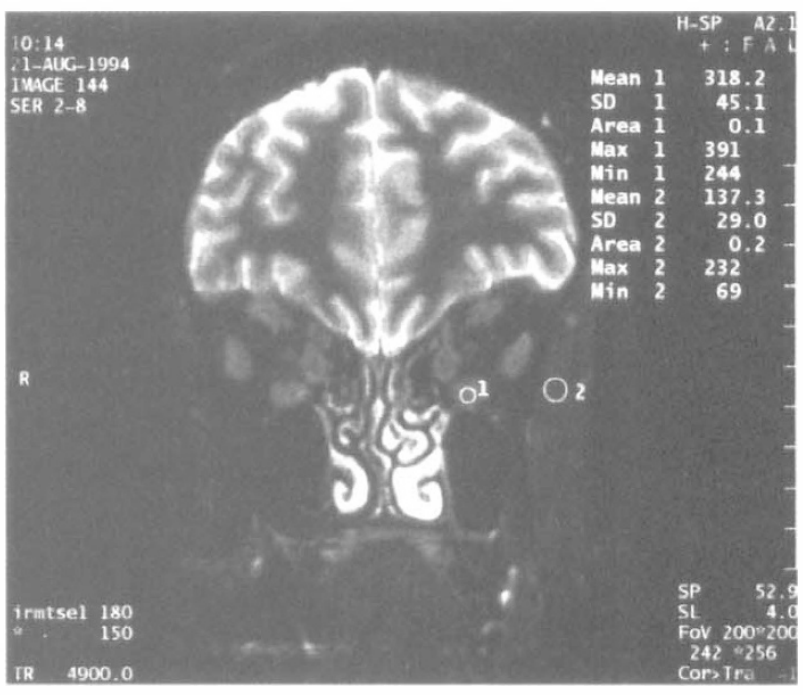

Fig. 2. A similar STIR sequence MRI scan showing the same patient as in Fig. 1. This shows reduced signal intensity in the affected extraocular muscle during the phase of regression.

most cases thyroid eye disease is mild but in some cases it is severe enough to require immune suppression and orbital radiotherapy. ${ }^{13}$

The early active ('wet') phase of soft tissue inflammation represents the stage of disease most responsive to radiotherapy and immune suppression. ${ }^{14}$ Hoh and co-worker ${ }^{11,12}$ found the SIR index of inflammatory activity in extraocular muscles correlated with restriction of extraocular movements and with clinical ratings.

The data presented here substantiate the finding that SIR values correlate with clinical disease. For a given patient serial SIR values correlate reliably with matched clinical disease activity scores. Serial SIR values for a patient provide an objective measure of disease activity and enhance clinical management and future treatment. This may be especially useful in cases where there is doubt concerning disease activity on clinical grounds.

Inflammatory activity in muscles seems to reflect overall disease activity as measured by the Mourits score. Previous studies have shown that the sign of thyroid eye disease that most closely correlates with disease severity is restriction of extraocular movements. ${ }^{11,15,16} \mathrm{CT}$ studies show that the likelihood of optic nerve compression is related to muscle cross-sectional area and muscle volume estimates. ${ }^{8,9}$ The T1-weighted MRI scans performed routinely with STIR sequence scans would also warn of imminent optic nerve compression. The superior soft tissue resolution of MRI and its ability to measure inflammatory activity in muscles in thyroid eye disease have meant it has superseded CT scanning as a first-line investigation in this condition.

Clinical measures of muscle function (uniocular fields of fixation) can be used to assess the phase of thyroid eye disease and monitor activity. ${ }^{16}$ When uniocular fields of fixation are used to monitor thyroid eye disease it has 


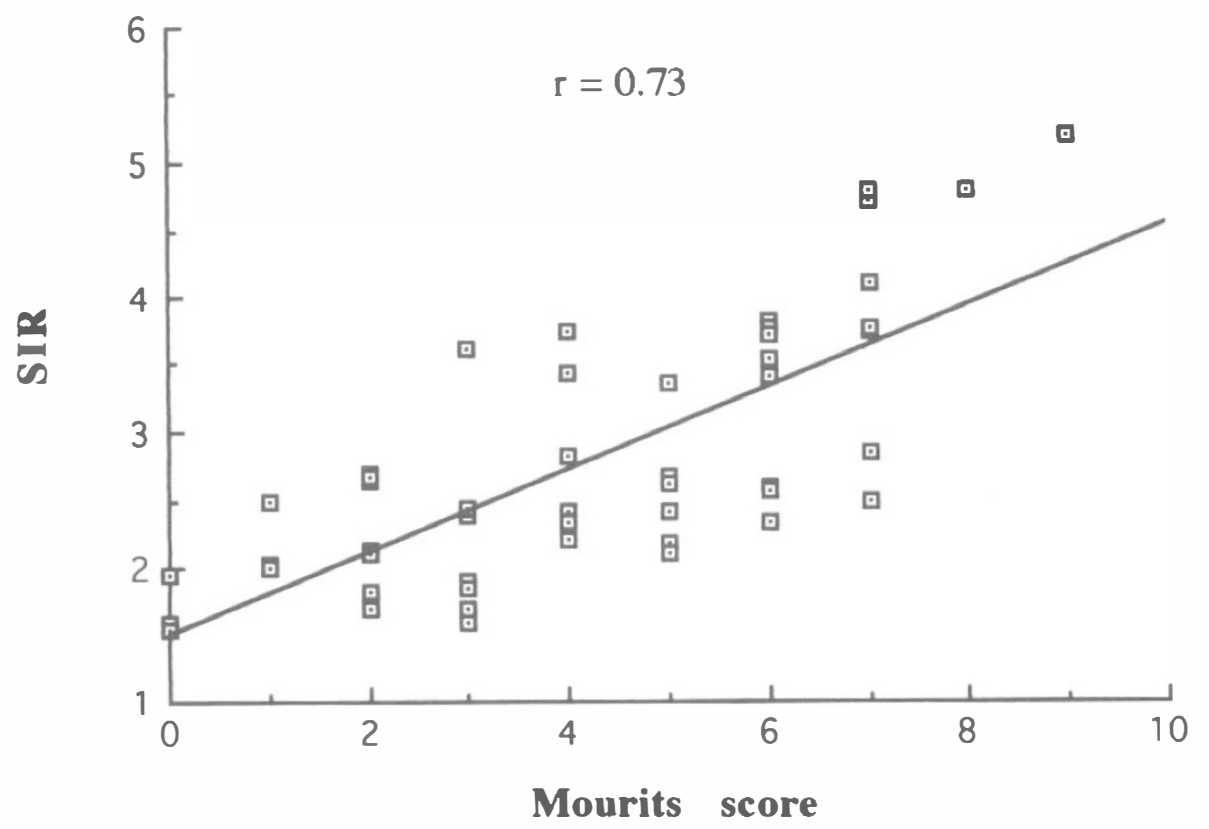

Fig. 3. The simple correlation between paired SIR values and Mourits scores $(\mathrm{r}=0.73)$.

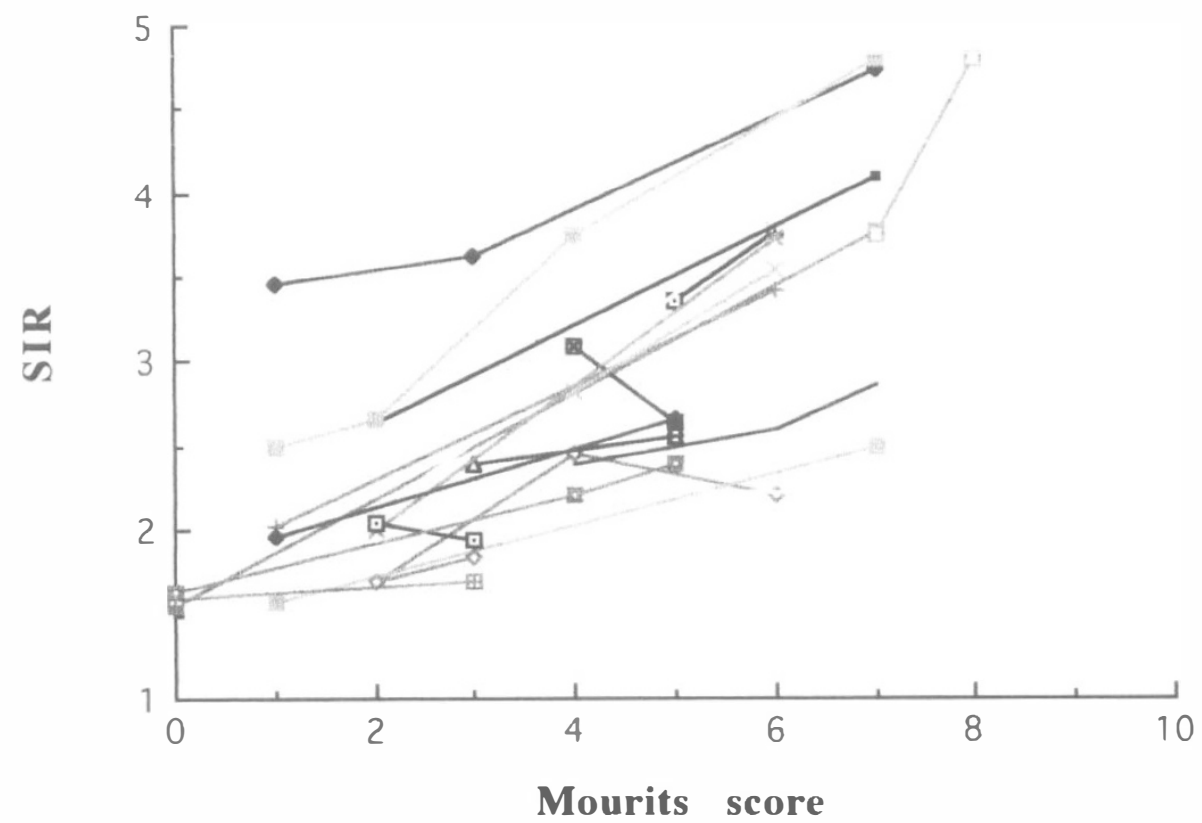

Fig. 4. Paired values of SIR values and Mourits scores on the same patient. The data for all patients are shown here. Disease is most active in the upper right-hand corner of the graph and least active in the lower left-hand corner. The direction of disease progression (and time) tends to be from the upper right to the lower left-hand corner of the graph.

been found that whilst solitary measures are of limited value, serial measures are more informative and reflect changes in disease activity. ${ }^{16}$ This, combined with the findings of the current paper, suggests that inflammatory changes in extraocular muscles provide a useful indicator of underlying inflammatory activity in thyroid eye disease. Serial measurements may help to assess whether there is still untreated inflammatory activity.

In conclusion, there is a 'good' linear correlation between MRI STIR sequence muscle brightness (SIR values) and the clinical features of inflammation in thyroid eye disease (Mourits scores). The changes in SIR values over time in an individual patient occurs in line with the change in clinical disease activity as measured by the Mourits score. This indicates that both values measure the underlying inflammatory disease activity. For treatment regimes designed with immune suppression in mind this provides a potentially useful measure of immune sensitivity. However, even in burntout thyroid eye disease muscle morphology and signal intensity do not return to normal. SIR values may remain slightly elevated compared with those in individuals who have never had thyroid eye disease. Further studies are required to establish the predictive value of SIR values for immune sensitivity in thyroid eye disease. 


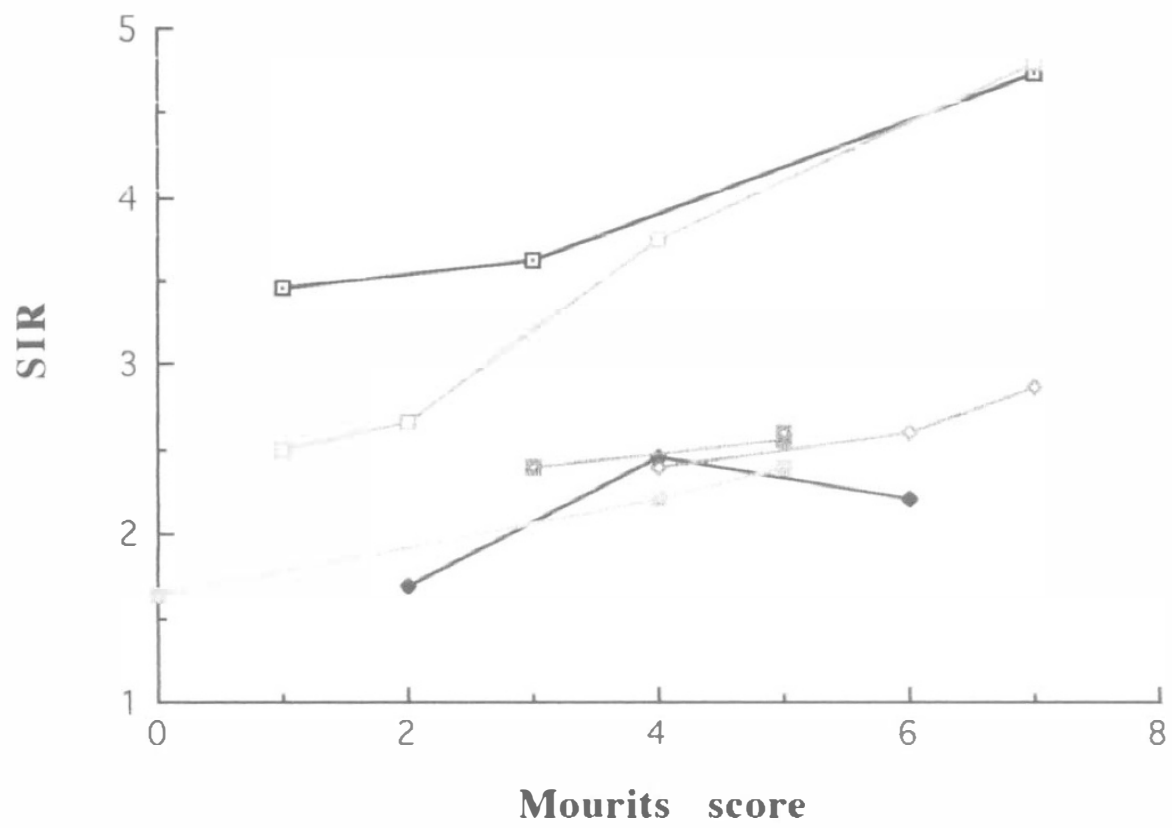

Fig. 5. Paired values of SIR values and Mourits scores on the same patient. Only the data for patients with more than two MRI scans are shown here. Otherwise the data are the same as those shown in Fig. 4.

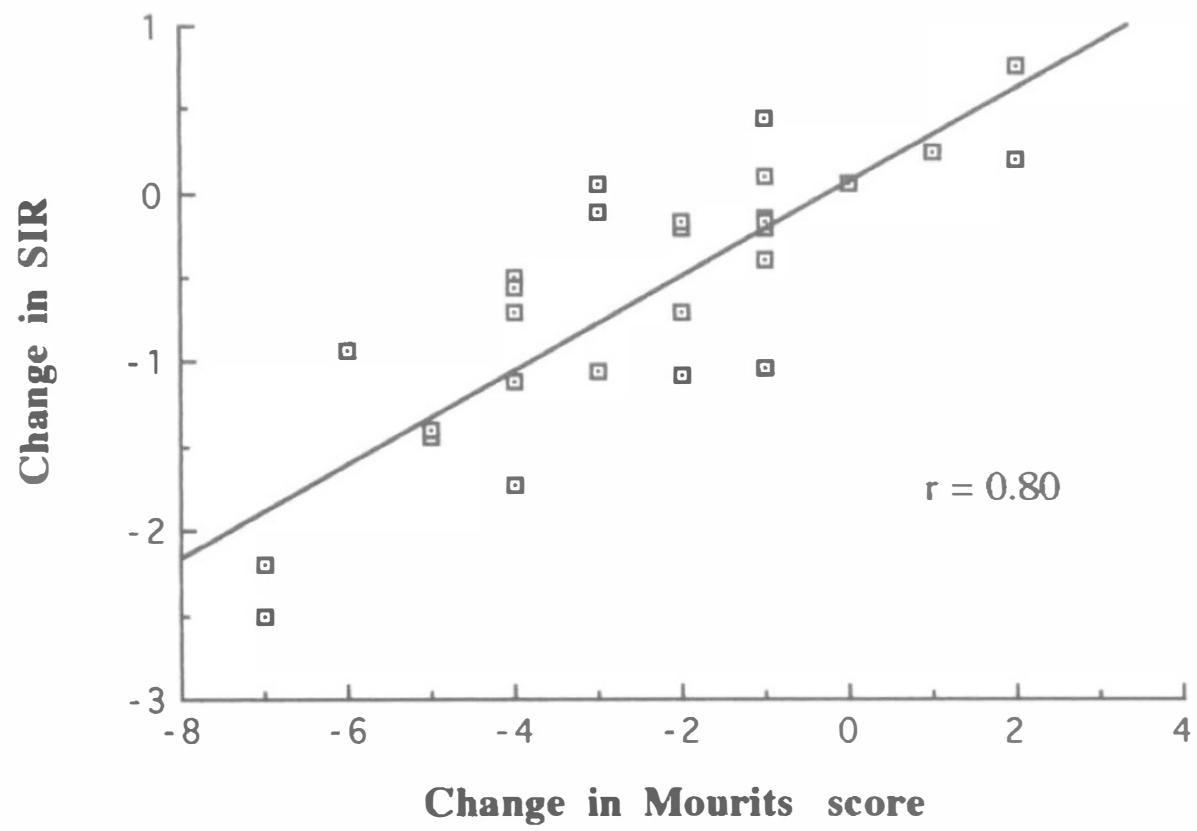

Fig. 6. A comparison of matched values for change in SIR value with change in Mourits score at consecutive visits. The data show a comparison that is highly statistically significant even when only the first pair value for each patient is used $(\mathrm{r}=0.80, \mathrm{p}<0.001)$.

We are very grateful to Kathryn Roberts and the Radiography Staff within the MRI Department at the Bristol Royal Infirmary for their help and support. We would also like to thank Mr John Sparrow and Ms Cathy Williams of the Bristol Eye Hospital for their advice.

\section{References}

1. Steel DHW, Potts MJ. Thyroid eye disease. In: Sparrow JM, Easty DL, editors. Oxford textbook of ophthalmology.

Oxford: Oxford University Press, 1999:722-30.

2. Bahn RS, Heufelder AE. Pathogenesis of Graves' ophthalmology. N Engl J Med 1993;329:1468-75.
3. Rundle FF, Wilson CW. Development and course of exophthalmos and ophthalmoplegia in Graves' disease with special reference to the effect of thyroidectomy. Clin Sci 1945;5:177-94.

4. Mourits MPH, Koorneef L, Wiersinga WM, Prummel MF, Berghant A, Gaag RVD. Clinical criteria for the assessment of disease activity in Graves' ophthalmopathy: a novel approach. Br J Ophthalmol 1989;73:639-44.

5. Prummell MF, Mourits MP, Berghout A, Krenning EP, van der Gaag R, Koornneef L, et al. Prednisolone and cyclosporine in the treatment of severe Graves' ophthalmopathy. N Engl J Med 1989;321:1353-9.

6. Werner SC. Classification of the eye changes of Graves' disease. J Clin Endocrinol Metab 1969;29:982-4. 
7. Werner SC. Modification of the classification of the eye changes of Graves' disease. Am J Ophthalmol 1977;83:725-7.

8. Hallin ES, Feldon SE. Graves' ophthalmopathy. II. Correlation of clinical signs with measures derived from computed tomography. Br J Ophthalmol 1988;72:678-82.

9. Hosten N, Sander B, Cordes M, Schubert CJ, Schörner W, Felix R. Graves' ophthalmopathy: MR imaging of the orbits. Radiology 1989;172:759-62.

10. Just M, Kahaly G, Higer HP, Rösler HP, Kutzner J, et al. Graves' ophthalmopathy: role of MR imaging in radiation therapy. Radiology 1991;179:187-90.

11. Hoh HB, Laitt RD, Wakely C, Kabala J, Goddard P, Potts MJ, et al. The STIR sequence MRI in the assessment of extraocular muscles in thyroid eye disease. Eye 1994;8:506-10.
12. Laitt RD, Hoh B, Wakeley C, Kabala J, Harrad R, Potts MJ, Goddard $\mathrm{P}$. The value of the short tau inversion recovery sequence in magnetic resonance imaging of thyroid eye disease. Br J Radiol 1994;67:244-7.

13. Claridge KG, Ghabrial R, Davis G, Tomlinson M, Goodman $\mathrm{S}$, Harrad RA, et al. Combined radiotherapy and immunosuppression in the management of thyroid eye disease. Eye 1997;11:717-22.

14. Hurbli T, Char DH, Harris J, Weaver K, Greenspan F, Sheline G. Radiation therapy for thyroid eye diseases. Am J Ophthalmol 1985;99:633-7.

15. Feldon SE, Muramatsu S, Weiner JM. Clinical classification of Graves' ophthalmopathy. Arch Ophthalmol 1984;102:1469-72. 16. Steel DHW, Hoh HB, Potts MJ, Harrad RA. Uniocular fields of fixation in thyroid eye disease. Eye 1995;9:348-51. 